\title{
Chitosan Enhances the In Vitro Surface Activity of Dilute Lung Surfactant Preparations and Resists Albumin-Induced Inactivation
}

\author{
YI Y. ZUO, HAMDI ALOLABI, ARASH SHAFIEI, NINGXI KANG, ZDENKA POLICOVA, PETER N. COX, EDGAR ACOSTA, \\ MICHAEL L. HAIR, AND A. WILHELM NEUMANN
}

Department of Mechanical and Industrial Engineering [Y.Y.Z., Z.P., M.L.H, A.W.N.], University of Toronto, Toronto, Ontario, M5S 3G8, Canada; Department of Chemical Engineering and Applied Chemistry [H.A., A.S., N.K., E.A.], University of Toronto, Toronto, Ontario, M5S 3E5, Canada; Department of Critical Care Medicine [P.N.C.], The Hospital for Sick Children, Toronto, Ontario, M5G 1X8, Canada

\begin{abstract}
Chitosan is a natural, cationic polysaccharide derived from fully or partially deacetylated chitin. Chitosan is capable of inducing large phospholipid aggregates, closely resembling the function of nonionic polymers tested previously as additives to therapeutic lung surfactants. The effects of chitosan on improving the surface activity of a dilute lung surfactant preparation, bovine lipid extract surfactant (BLES), and on resisting albumin-induced inactivation were studied using a constrained sessile drop (CSD) method. Also studied in parallel were the effects of polyethylene glycol (PEG, $10 \mathrm{kD}$ ) and hyaluronan (HA, $1240 \mathrm{kD}$ ). Both adsorption and dynamic cycling studies showed that chitosan is able to significantly enhance the surface activity of $0.5 \mathrm{mg} / \mathrm{mL}$ BLES and to resist albumin-induced inactivation at an extremely low concentration of $0.05 \mathrm{mg} / \mathrm{mL}, 1000$ times smaller than the usual concentration of PEG and 20 times smaller than HA. Optical microscopy found that chitosan induced large surfactant aggregates even in the presence of albumin. Cytotoxicity tests confirmed that chitosan has no deleterious effect on the viability of lung epithelial cells. The experimental results suggest that chitosan may be a more effective polymeric additive to lung surfactant than the other polymers tested so far. (Pediatr Res 60: 125-130, 2006)
\end{abstract}

A iming at decreasing the cost of surfactant replacement therapy and improving its efficacy in treating ARDS, Taeusch et al. (1) suggested the use of low-cost, water-soluble nonionic polymers, such as dextran, PEG, and polyvinylpyrrolidone (PVP), as additives to therapeutic lung surfactants. Both in vitro (1-6) and in vivo (7-9) trials have shown that these nonionic polymers can significantly improve the surface activity of different therapeutic lung surfactants and effectively reverse inactivation due to a variety of inhibitory substances.

More recently, Lu et al. $(10,11)$ reported the use of an anionic polymer, HA, as a surfactant additive. Both in vitro (10) and in vivo (11) tests showed that the addition of HA at different molecular weights to various therapeutic lung sur-

Received September 21, 2005; accepted March 14, 2006.

Correspondence: A.W. Neumann, Ph.D., Department of Mechanical and Industrial Engineering, University of Toronto, 5 King's College Road, Toronto, ON, M5S 3G8, Canada; e-mail: neumann@mie.utoronto.ca

This work was supported by a grant from the Canadian Institutes of Health Research (MOP-38037) and an Open Fellowship from the University of Toronto to Y.Y.Z. factants can effectively reverse serum- and meconium- induced inactivation. These studies, therefore, tentatively proved the feasibility of using an ionic polymer as a lung surfactant additive. Following these studies, we investigate here the use of a cationic polymer, chitosan, as a potential lung surfactant additive.

Chitosan is a natural polysaccharide composed of linear $\beta$ - $(1 \rightarrow 4)$-linked 2-amino-2-deoxy- $\beta$-D-glucan combined with glycosidic linkages (12). It is derived from fully or partially deacetylated chitin, which is extracted from crustacean shells. Chitosan is also a polyelectrolyte with a positively charged backbone and is readily soluble in slightly acidic conditions (12). Chitosan was proven to be biodegradable, biocompatible, bioadhesive, and nontoxic in a range of toxicity tests (13). Because of these desirable properties, it has been extensively used in a variety of food, cosmetic, and pharmaceutical fields. Specifically, chitosan has been extensively used in drug delivery (13), including pulmonary drug delivery (12).

Chan and co-workers (14-17) have recently reported that chitosan can be used as a potent membrane perturbant to destabilize dipalmitoyl phosphatidylcholine (DPPC) bilayers and cause fusion of small DPPC vesicles to form large multilamellar structures. This function of chitosan closely resembles the effect of nonionic polymers in improving surface activity of therapeutic lung surfactants by inducing large surfactant aggregates $(5,6)$ and hence leads us to consider its potential use as a lung surfactant additive. In this study, the effects of chitosan on surface activity of a dilute therapeutic lung surfactant, BLES (BLES Biochemicals Inc, London, ON, Canada), and on the resistance to albumin-induced inactivation are investigated using a CSD method (18). To further characterize the performance of chitosan, the effects of PEG $(10 \mathrm{kD})$, which is the most effective nonionic polymer tested so far $(1,5)$, and, HA (1240 kD), i.e. the most effective HA

Abbreviations: ADSA, axisymmetric drop shape analysis; ARDS, acute respiratory distress syndrome; BLES, bovine lipid extract surfactant; CR, compression ratio; CSD, constrained sessile drop; HA, hyaluronan; PEG, polyethylene glycol; $\gamma_{\text {min }}$, minimum surface tension during dynamic cycling 
molecular weight $(10,11)$, are also studied under the same conditions and compared with the effects of chitosan.

\section{METHODS}

Materials. BLES is a therapeutic lung surfactant and is commercially available. It is prepared by organic extraction from bronchopulmonary bovine lung lavage. BLES contains approximately $98 \%$ phospholipids and $2 \%$ proteins by weight. The main tensioactive component in BLES is DPPC, accounting for approx. $45 \%$. The only protein components in BLES are low molecular weight hydrophobic proteins, SP-B and SP-C. High molecular weight hydrophilic proteins, SP-A and SP-D, have been removed during the extraction with organic solvents. BLES was stored frozen with an initial concentration of $27 \mathrm{mg} / \mathrm{mL}$. It was diluted to $0.5 \mathrm{mg} / \mathrm{mL}$ by a salt solution of $0.6 \% \mathrm{NaCl}$ and $1.5 \mathrm{mM} \mathrm{CaCl}_{2}$ on the day of experiments. The $\mathrm{pH}$ of the diluted BLES preparation was measured to be $5.6(18)$.

Chitosan (Cat. No. 448869, M 612 kD (19), degree of deacetylation 75-85\%) was purchased from Aldrich Chemical (Milwaukee, WI). A concentrated chitosan solution was prepared by dissolving $100 \mathrm{mg}$ chitosan in $9 \mathrm{~mL} 0.05 \mathrm{M}$ hydrochloric acid with overnight stirring at room temperature. After complete dissolution, the solution had a $\mathrm{pH}$ of 5. The chitosan solution was then diluted to final concentrations of $0.01,0.05$, and $0.1 \mathrm{mg} / \mathrm{mL}$ and mixed with $0.5 \mathrm{mg} / \mathrm{mL}$ BLES suspension, respectively. This range of chitosan concentrations was chosen because of previous studies in which chitosan effectively induced fusion of DPPC vesicles (14-17). The $\mathrm{pH}$ of the resultant mixtures of BLES and chitosan was measured to be 5.5, similar to that of BLES alone.

PEG (Cat. No. P-6667, 10 kD), HA [Cat. No. H9390, 1240 kD (10,11)], and BSA (Cat. No. A-0281, minimum 99\%, essentially globulin and fatty acid free) were purchased from Sigma Chemical Co. (St. Louis, MO). A standard PEG concentration of $50 \mathrm{mg} / \mathrm{mL}$ defined in previous studies $(1,6-9)$ was used. A series of HA concentrations ranging from 0.1 to $2.5 \mathrm{mg} / \mathrm{mL}$ were tested. An albumin concentration of $2.5 \mathrm{mg} / \mathrm{mL}$ was used. This concentration is far less than the average albumin concentration in ARDS alveolar fluid, i.e. $25 \mathrm{mg} / \mathrm{mL}$ reported by Ishizaka et al. (20). However, previous in vitro studies have shown that at such a concentration albumin was sufficient to inactivate a dilute lung surfactant preparation, such as the $0.5 \mathrm{mg} / \mathrm{mL}$ BLES used here $(2,4)$.

Measurements of surface activity. Surface activity of different preparations was examined using a novel experimental arrangement, CSD, recently developed in the authors' laboratory (18). Detailed experimental protocol has been described before $(18,21)$. Briefly, to ensure a clean air-water interface before adsorption, formation of a sessile drop was completed within $0.5 \mathrm{~s}$, precisely controlled by a programmable motor-controller (18705/6, Oriel Instruments, Stratford, CT). Subsequently, the droplet was left undisturbed to allow adsorption of a lung surfactant film. Complete film formation was indicated by decreasing and maintaining surface tension at an equilibrium value of approximately $25 \mathrm{~mJ} / \mathrm{m}^{2}$ (22). Dynamic cycling was commenced immediately after film formation. It was facilitated by periodically adding and withdrawing test liquid into and out of the droplet by means of a motor-driven syringe at a frequency of 20 cycles per min. Three different CR, defined as the ratio of the total area reduction upon compression to the initial surface area before compression, were tested, i.e. 15,20 , and $30 \%$, corresponding to the physiologically relevant range (23).

A CCD camera (Model 4815-5000, Cohu Corp., Poway, CA) was used to acquire images throughout the experiments but at different acquisition rates, i.e. 10 images per second for adsorption and 30 for dynamic cycling. Surface tension, area, and volume of the droplet were determined by ADSA, in which the experimental drop profile was fitted to a series of theoretical profiles given by the classical Laplace equation of capillarity until the best match was found (24).

Optical microscopy. The morphology change of surfactant aggregates in aqueous suspensions due to the addition of albumin and/or chitosan was checked using an optical microscope (Olympus IMT-2, Lake Success, NY). Images of different surfactant preparations under the microscope were taken by a high-resolution digital camera (Sony XCD-SX900, Toronto, ON, Canada).

Viscosity measurements. Viscosity of polymer solutions was measured using a falling ball viscometer (GV-2200, Gilmont Instruments, Barrington, IL), which was calibrated by distilled water at a temperature of $37 \pm 0.2^{\circ} \mathrm{C}$.

Cytotoxicity studies. The viability of human-derived tracheal/bronchial epithelial cell tissues (MaTtek EpiAirway, Ashland, MA) was evaluated using the MTT test (25). The tissues were immersed for $6 \mathrm{~h}$ in surfactant preparations (cilia exposed to air). Then, the tissues were dipped into a tetrazolium salt (MTT) solution. MTT is converted to insoluble purple formazan by living cells. Formazan was extracted with isopropanol and the absorbance $(570 \mathrm{~nm})$ of this solution was measured using an Ocean Optics HR2000 spectrophotometer (Ocean Optics, Inc., Dunedin, FL). The viability is the fraction of the absorbance of the sample divided by the absorbance of the tissue dipped in phosphate-buffered solution.

Statistical analysis. Data are expressed as mean \pm SEM $(n>3$ unless otherwise indicated). Group differences were analyzed by one-way ANOVA with the Bonferroni, Scheffé, and Tukey post hoc tests. A $p<0.05$ was considered statistically significant.

\section{RESULTS}

Adsorption. Figure 1 shows the adsorption curves of different BLES preparations with and without the addition of albumin and/or different polymers. Note that: 1) the $0.5 \mathrm{mg} / \mathrm{mL}$ BLES reaches surface tension equilibrium after about $150 \mathrm{~s}$, in good agreement with previously published results $(5,21)$. 2) The presence of $2.5 \mathrm{mg} / \mathrm{mL}$ albumin significantly increases the adsorption time. A surface tension plateau at $54 \pm 1 \mathrm{~mJ} / \mathrm{m}^{2}$ is reached soon after the onset of adsorption. This plateau corresponds to the equilibrium surface tension of albumin $(2,26)$ and indicates rapid monopolization of the air-water interface by albumin due to a competitive adsorption mechanism (2,26-28). After approximately $300 \mathrm{~s}$, the surface tension starts to slowly decrease again and eventually reaches the equilibrium value of a predominantly phospholipid film after approximately $1800 \mathrm{~s}$. This second surface tension decrease from the equilibrium value of albumin to that of phospholipids indicates the replacement of albumin at the air-water interface by the lung surfactant. 3) The addition of water-soluble polymers, i.e. PEG $(50 \mathrm{mg} / \mathrm{mL}), \mathrm{HA}(1.0 \mathrm{mg} / \mathrm{mL})$, and chitosan $(0.05 \mathrm{mg} / \mathrm{mL})$, significantly decreases the adsorption time even in the presence of albumin. The adsorption curves of BLES with the addition of polymers (curves $c-h$ ) coincide and show similarly rapid adsorption. An equilibrium surface tension of $24 \mathrm{~mJ} / \mathrm{m}^{2}$ is reached within $20 \mathrm{~s}$, in good agreement with PEG results published previously (5). Nevertheless, it should be noted that chitosan, at a concentration 1000 times

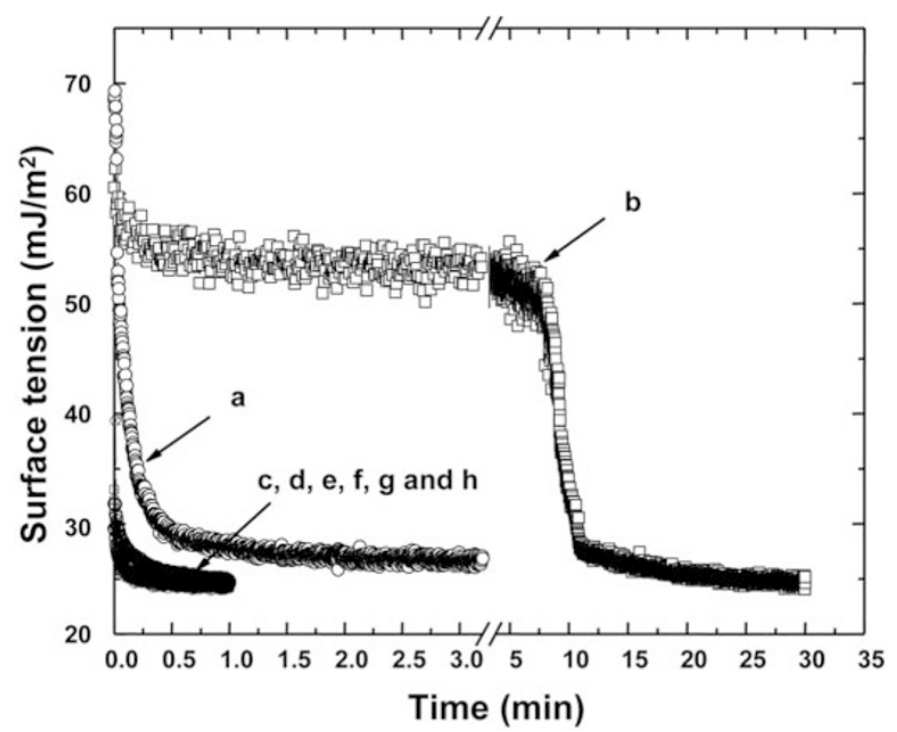

Figure 1. Adsorption curves for $(a) 0.5 \mathrm{mg} / \mathrm{mL}$ BLES; $(b)$ BLES +2.5 $\mathrm{mg} / \mathrm{mL}$ albumin; $(c)$ BLES $+50 \mathrm{mg} / \mathrm{mL}$ PEG; $(d)$ BLES $+1.0 \mathrm{mg} / \mathrm{mL}$ HA; (e) BLES + $0.05 \mathrm{mg} / \mathrm{mL}$ chitosan; $(f)$ BLES + albumin + PEG; $(g)$ BLES + albumin + HA; $(h)$ BLES + albumin + chitosan. The adsorption curves with the addition of PEG, HA, or chitosan, i.e., curves $c-h$, coincide. 
smaller than PEG and 20 times smaller than HA, improves the adsorption of BLES to the same extent as PEG and HA.

The effect of HA at a series of concentrations on the adsorption of $0.5 \mathrm{mg} / \mathrm{mL}$ BLES $+2.5 \mathrm{mg} / \mathrm{mL}$ albumin was tested. It was found that in the range of 0.1 to $1.5 \mathrm{mg} / \mathrm{mL}$, HA effectively improves adsorption (adsorption time $<20 \mathrm{~s}$ ). However, when its concentration is increased to $2.5 \mathrm{mg} / \mathrm{mL}$, it no longer reverses albumin-induced inactivation effectively (adsorption time $300 \mathrm{~s}$ ). Therefore, $0.1-1.5 \mathrm{mg} / \mathrm{mL}$ may represent an optimal range of HA concentration to reverse the inactivation of $2.5 \mathrm{mg} / \mathrm{mL}$ albumin in a $0.5 \mathrm{mg} / \mathrm{mL}$ BLES preparation.

In addition to $0.05 \mathrm{mg} / \mathrm{mL}$, chitosan at 0.01 and $0.1 \mathrm{mg} / \mathrm{mL}$ was also tested. At all three concentrations, the addition of chitosan decreases the adsorption time to $<20 \mathrm{~s}$ in spite of the presence of albumin. No significant difference in the effectiveness of decreasing adsorption time is found between these concentrations or when using PEG at $50 \mathrm{mg} / \mathrm{mL}$ and $\mathrm{HA}$ in the range of $0.1-1.5 \mathrm{mg} / \mathrm{mL}$.

Dynamic cycling. Figure 2 shows $\gamma_{\min }$ of BLES in the absence of albumin, with and without the addition of polymers. It is noted that at a high CR (30\%), all the substances (with the exception of $0.01 \mathrm{mg} / \mathrm{mL}$ chitosan) produce a similar low $\gamma_{\min }$ as BLES alone. However, at low (15\%) and moderate $(20 \%) \mathrm{CR}$, the addition of either PEG, HA, or chitosan significantly decreases the $\gamma_{\min }$ of BLES. The effect of chitosan on decreasing the $\gamma_{\min }$ is clearly concentration dependent. At $0.01 \mathrm{mg} / \mathrm{mL}$, chitosan does not significantly change the $\gamma_{\min }$ at $20 \% \mathrm{CR}$; however, at 0.05 and $0.1 \mathrm{mg} / \mathrm{mL}$, chitosan significantly decreases the $\gamma_{\min }$ at both 15 and $20 \%$ CR. Compared with PEG at $50 \mathrm{mg} / \mathrm{mL}$ and $\mathrm{HA}$ at $1.0 \mathrm{mg} / \mathrm{mL}$, chitosan at these two concentrations shows significantly more improvement in surface tension decrease.

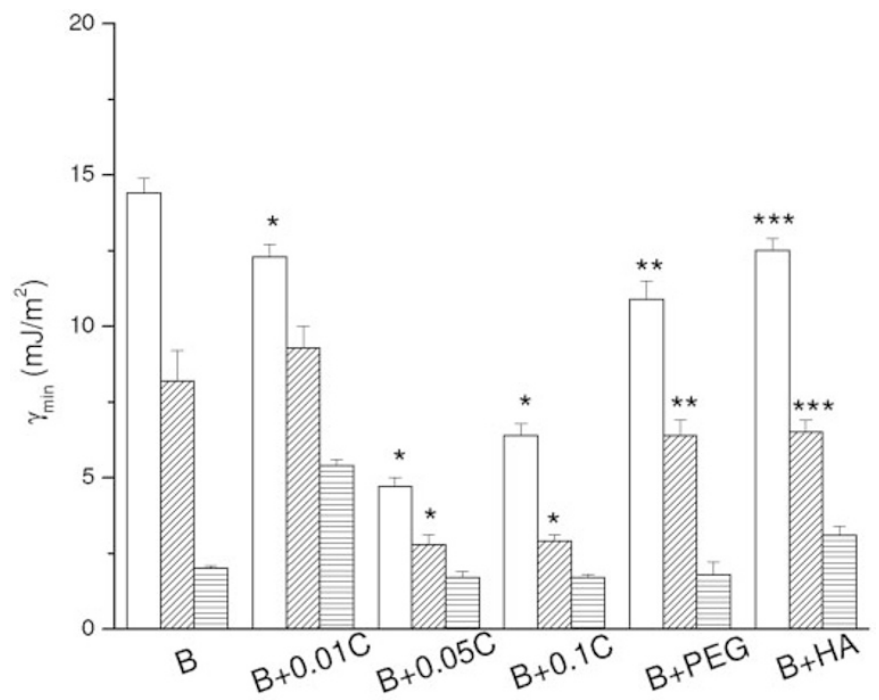

Figure 2. Minimum surface tensions $\left(\gamma_{\min }\right)$ in the absence of albumin at three CR: $\square, 15 \%$; 包, 20\%; and 貝 30\%. B: $0.5 \mathrm{mg} / \mathrm{mL}$ BLES; B + 0.01C: BLES $+0.01 \mathrm{mg} / \mathrm{mL}$ chitosan; B + 0.05C: BLES + $0.05 \mathrm{mg} / \mathrm{mL}$ chitosan; B + 0.1C: BLES + $0.1 \mathrm{mg} / \mathrm{mL}$ chitosan; B + PEG: BLES + $50 \mathrm{mg} / \mathrm{mL}$ PEG; B + HA: BLES $+1 \mathrm{mg} / \mathrm{mL}$ HA. ${ }^{*} p<0.01$ for comparison between BLES + chitosan and BLES alone; ** $p<0.01$ for comparison between BLES + PEG and BLES $+0.05 \mathrm{mg} / \mathrm{mL}$ chitosan; $* * * p<0.01$ for comparison between BLES + HA and BLES $+0.05 \mathrm{mg} / \mathrm{mL}$ chitosan.
Figure 3 shows $\gamma_{\min }$ of BLES in the presence of $2.5 \mathrm{mg} / \mathrm{mL}$ albumin, with and without the addition of polymers. $\gamma_{\min }$ of BLES alone is replotted from Figure 2 as a control. Note that: 1) Albumin significantly inactivates the dilute BLES, i.e. it increases the $\gamma_{\min }$ at all CR. 2) The addition of either PEG or chitosan counteracts the inhibitory effect of albumin, i.e. it decreases the $\gamma_{\min }$ to values even lower than BLES alone at 15 and $20 \%$ CR. 3) The effect of chitosan on resisting inactivation is concentration dependant. Here, due to the unsatisfactory performance in the absence of albumin (Fig. 2), the concentration of $0.01 \mathrm{mg} / \mathrm{mL}$ was not tested. At both 0.05 and $0.1 \mathrm{mg} / \mathrm{mL}$, chitosan effectively resists inactivation. Especially at $0.1 \mathrm{mg} / \mathrm{mL}$, chitosan decreases $\gamma_{\min }$ at all CR to values lower than those for PEG as additive as well as for BLES alone.

Surprisingly, HA at none of the tested concentrations in the range of $0.1-2.5 \mathrm{mg} / \mathrm{mL}$ can restore the dynamic surface activity of BLES, although it helps to improve adsorption. When decreasing the albumin concentration to $1.0 \mathrm{mg} / \mathrm{mL}$, however, $1.0 \mathrm{mg} / \mathrm{mL} \mathrm{HA}$ is capable of reversing inactivation, as shown in Figure 4.

Morphology change. Figure 5 shows the optical microscope images of $0.5 \mathrm{mg} / \mathrm{mL}$ BLES with/without albumin and/or chitosan. It is noted that BLES alone shows a clear unilaminar structure of single vesicles or small aggregates of vesicles. Addition of $2.5 \mathrm{mg} / \mathrm{mL}$ albumin changes the original morphology of BLES to structures of rather smaller aggregates with features of higher curvature. Addition of 0.05 $\mathrm{mg} / \mathrm{mL}$ chitosan to either BLES or the mixture of BLES and albumin causes formation of significantly larger aggregates with a multilaminar structure.

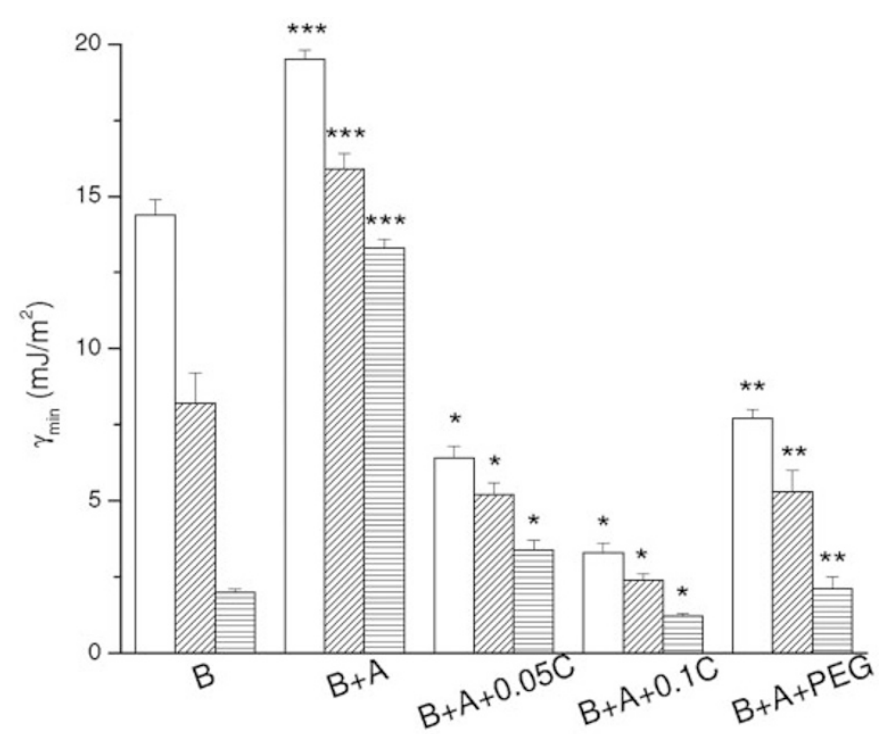

Figure 3. Minimum surface tensions $\left(\gamma_{\min }\right)$ in the presence of albumin at three CR: $\square, 15 \%$; 四, 20\%; and 目, 30\%. B: $0.5 \mathrm{mg} / \mathrm{mL}$ BLES; B +A: BLES $+2.5 \mathrm{mg} / \mathrm{mL}$ albumin; B + A + 0.05C: BLES + albumin $+0.05 \mathrm{mg} / \mathrm{mL}$ chitosan; B + A + 0.1C: BLES + albumin + $0.1 \mathrm{mg} / \mathrm{mL}$ chitosan; B + A + PEG: BLES + albumin $+50 \mathrm{mg} / \mathrm{mL}$ PEG. $* p<0.01$ for comparison between BLES + albumin + chitosan and BLES + albumin; $* * p<0.01$ for comparison between BLES + albumin + PEG and BLES + albumin + 0.1 $\mathrm{mg} / \mathrm{mL}$ chitosan; $* * * p<0.01$ for comparison between BLES + albumin and BLES alone. 


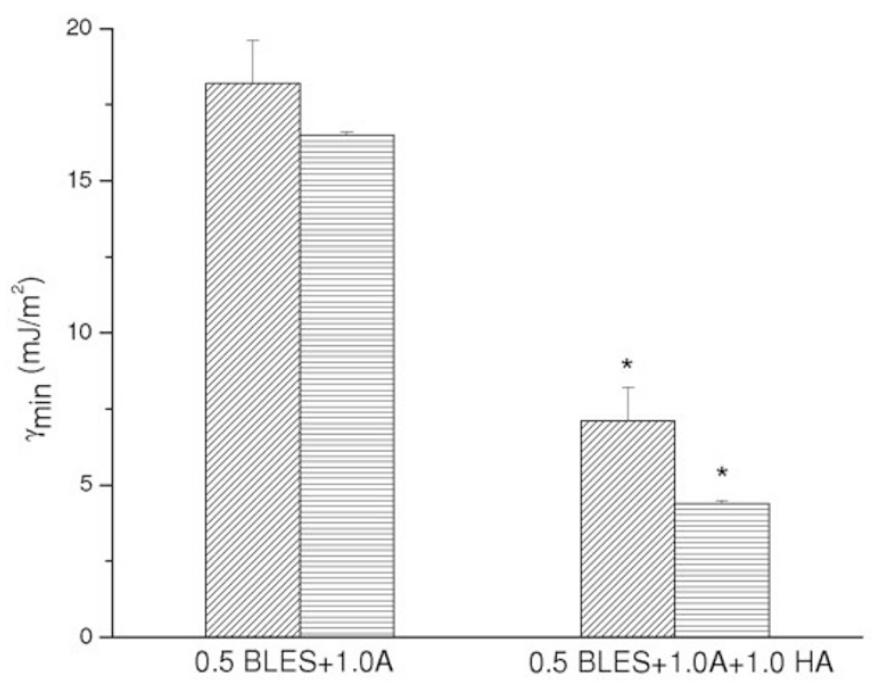

Figure 4. Minimum surface tension $\left(\gamma_{\min }\right)$ of $0.5 \mathrm{mg} / \mathrm{mL}$ BLES +1.0 $\mathrm{mg} / \mathrm{mL}$ albumin with and without the addition of $1.0 \mathrm{mg} / \mathrm{mL}$ HA at two CR: 四, 20\%; 冒, 30\%. ${ }^{*} p<0.01$ for comparison between with and without HA.
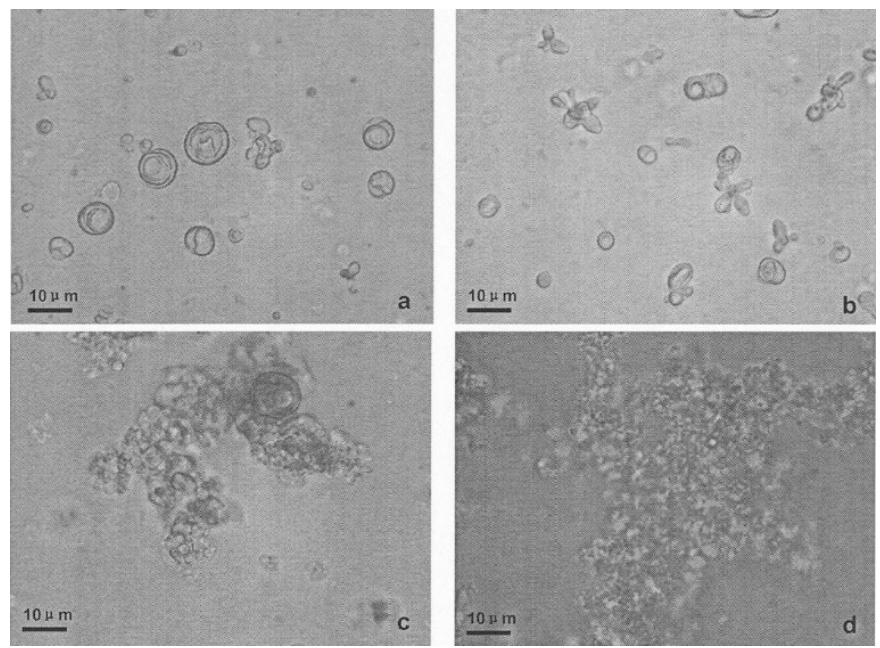

Figure 5. Optical microscope images of (a) $0.5 \mathrm{mg} / \mathrm{mL}$ BLES; (b) BLES + $2.5 \mathrm{mg} / \mathrm{mL}$ albumin; (c) BLES $+0.05 \mathrm{mg} / \mathrm{mL}$ chitosan; (d) BLES + albumin + chitosan.

\section{DISCUSSION}

The presence of albumin inactivates the dilute BLES preparation, i.e. it not only increases the adsorption time by more than 10 -fold but also significantly raises the minimum surface tension at all tested CR. Adding polymers (i.e. PEG, HA, or chitosan) significantly increases the surface activity of dilute lung surfactant preparations and resists the albumin-induced inactivation. Among the tested polymers, the improvement in the surface activity of $0.5 \mathrm{mg} / \mathrm{mL}$ BLES is found to be in the order of $0.1 \mathrm{mg} / \mathrm{mL}$ chitosan $>0.05 \mathrm{mg} / \mathrm{mL}$ chitosan $>$ $50 \mathrm{mg} / \mathrm{mL}$ PEG $>1.0 \mathrm{mg} / \mathrm{mL} \mathrm{HA}>0.01 \mathrm{mg} / \mathrm{mL}$ chitosan. The addition of $1.0 \mathrm{mg} / \mathrm{mL}$ HA improves adsorption in the presence of $2.5 \mathrm{mg} / \mathrm{mL}$ albumin and restores dynamic surface activity in the presence of $1.0 \mathrm{mg} / \mathrm{mL}$ albumin, but not at $2.5 \mathrm{mg} / \mathrm{mL}$ albumin. The addition of $0.01 \mathrm{mg} / \mathrm{mL}$ chitosan only improves adsorption but presents very limited beneficial effects on dynamic surface activity. At both 0.05 and 0.1 $\mathrm{mg} / \mathrm{mL}$, chitosan significantly enhances surface activity and resistance to inactivation due to $2.5 \mathrm{mg} / \mathrm{mL}$ albumin more effectively than PEG and HA. It is notable that chitosan is able to decrease $\gamma_{\min }$ to a lower level than PEG at the same CR. It also shows these beneficial effects at a concentration 1000 times smaller than the standard concentration of PEG (10 kD), i.e. $50 \mathrm{mg} / \mathrm{mL}$, defined in previous studies $(1,6-9)$. Therefore, chitosan appears to be the most effective lung surfactant additive tested so far with BLES.

A direct consequence of decreasing the polymer concentration is a significant decrease in solution viscosity, which is a general concern in drug delivery. A $0.05 \mathrm{mg} / \mathrm{mL}$ solution of chitosan at $37^{\circ} \mathrm{C}$ has a viscosity of $0.77 \mathrm{cP}(n=3)$, close to that of distilled water (i.e. $0.70 \mathrm{cP}$ ). This viscosity is less than half of that of $50 \mathrm{mg} / \mathrm{mL}$ PEG [i.e. $1.65 \mathrm{cP}(n=3)]$. Low polymer concentrations would also help to minimize the osmotic stress in vivo, which minimizes the possibility of polymer-induced imbalance in lung water, i.e. it is a desirable effect in the treatment of ARDS $(28,29)$. The cytotoxicity tests support this hypothesis. Specifically, the viability of cells exposed to $0.5 \mathrm{mg} / \mathrm{mL}$ BLES was $93 \pm 6 \%$, which is comparable to the viability obtained for $0.5 \mathrm{mg} / \mathrm{mL}$ BLES +0.1 $\mathrm{mg} / \mathrm{mL}$ chitosan, i.e. $83 \pm 16 \%$. In contrast, the viability of the cells exposed to $0.5 \mathrm{mg} / \mathrm{mL}$ BLES $+50 \mathrm{mg} / \mathrm{mL}$ PEG was only $46 \pm 3 \%$.

Similar to nonionic polymers, chitosan is not surface active [equilibrium surface tension $67.4 \pm 0.3 \mathrm{~mJ} / \mathrm{m}^{2}(n=7)$ at $0.05 \mathrm{mg} / \mathrm{mL}$ ]. However, the underlying mechanism of chitosan to enhance surface activity of lung surfactant may differ from that of nonionic polymers. Both experimental $(5,6)$ and theoretical (28) studies support the notion that the nonionic polymers improve the surface activity of lipid extract surfactant by a depletion-attraction mechanism. It has been demonstrated that in a pure phospholipid vesicle system, PEG at certain molecular weights and concentrations can induce a depletion-attraction force that promotes the formation of large phospholipid aggregates (30). Large aggregates are known to be more surface active than their smaller counterpart both in vitro (31) and in vivo (32). Theoretical study has established that the depletion attraction force is proportional to the aggregate radius (28). Thus, larger aggregates would experience a larger push to the interface and also deliver more surfactant to the interface.

The large phospholipid aggregates induced by chitosan in BLES (Fig. 5) occur possibly due to a mechanism different from or combined with depletion-attraction. Fang et al. (1517) found that chitosan induces fusion of small DPPC vesicles to form large lamellar structures by facilitating a gel to liquid crystalline phase transition due to electrostatic interactions between the amine groups of chitosan and the phospholipid head groups. The $\mathrm{p} K_{\mathrm{a}}$ of the amine groups in chitosan has been reported to be around 6.3-7.5 depending on the degree of deacetylation $(12,33)$. Hence, in the alveolar lining layer [pH 6.9 (34)], the amino groups of chitosan are partially positively charged and therefore may induce electrostatic binding with the anionic phospholipids. It was also reported that the binding between chitosan and anionic surfactants in acidic conditions is irreversible, i.e. after rising to neutral $\mathrm{pH}$, they remain bound (35). This minimizes the risk that chitosan 
nonspecifically binds to other surfaces (e.g. the airway tissues) after in vivo instillation.

The present study also suggests that chitosan is more effective than PEG and HA in resisting albumin-induced inactivation. However, this beneficial effect is not due to direct interaction of chitosan and albumin. To rule out this possibility, surface tension of albumin $(2.5 \mathrm{mg} / \mathrm{mL})$ and chitosan $(0.05 \mathrm{mg} / \mathrm{mL})$ mixture was measured and found to be $50 \pm$ $1 \mathrm{~mJ} / \mathrm{m}^{2}(n=4)$. This surface tension is only slightly lower than the equilibrium value of albumin alone, i.e. $54 \pm$ $1 \mathrm{~mJ} / \mathrm{m}^{2}$, measured in this study and reported elsewhere $(2,26)$. The surface tension decrease due to the addition of chitosan may indeed indicate some nonspecific electrostatic and/or hydrophilic binding between chitosan and albumin. However, the only slight difference in equilibrium surface tension with/without chitosan also suggests that chitosan does not affect albumin adsorption significantly. In addition, observation of the albumin-chitosan mixture under the optical microscope found no flocculation or aggregation, which further rules out the possibility that direct interaction between albumin and chitosan is responsible for the reversal of surfactant inactivation.

The present adsorption study (Fig. 1) supports the notion that that the water-soluble serum proteins, such as albumin, inactivate lung surfactant due to a competitive adsorption mechanism, i.e. by rapidly adsorbing to the air-water interface and hence creating a steric and/or electrostatic barrier for surfactant adsorption $(6,28)$. To resist or reverse the inactivation, the phospholipid components of lung surfactant must overcome these barriers by adsorbing more rapidly than albumin and/or effectively replacing the albumin molecules at the interface. Chitosan may outperform the nonionic polymers in mitigating the electrostatic barrier imposed by albumin by providing extra positive charges, similar to the function of lung surfactant proteins $(21,36,37)$.

Despite the fact that chitosan has significantly improved the surface activity of BLES, there are reports showing that polycations inactivated lung surfactants $(38,39)$, probably by disrupting the charge balance between anionic phospholipids and positively charged surfactant proteins. The deleterious effects were found to be dependent on the cationic additives/ surfactant phospholipid ratios $(38,39)$. These findings are consistent with the present study using ionic polymers (i.e. chitosan and HA). For instance, addition of $2.5 \mathrm{mg} / \mathrm{mL}$ HA to $0.5 \mathrm{mg} / \mathrm{mL}$ BLES impairs adsorption; however, previous studies showed that $2.5 \mathrm{mg} / \mathrm{mL}$ HA improved the surface activity of $1.25 \mathrm{mg} / \mathrm{mL}$ therapeutic surfactants $(10,11)$, i.e. at a concentration higher than the BLES concentration in the present study. Maintaining the ratio of surfactant to polymer, i.e. using a HA concentration of $1.0 \mathrm{mg} / \mathrm{mL}$, led indeed to a restoration of rapid adsorption even in the presence of $2.5 \mathrm{mg} / \mathrm{mL}$ albu$\mathrm{min}$. These results underline the importance of electrostatic interactions in the normal biophysical function of lung surfactant. Hence, it may be preferable to define an "optimal (phospholipid/polymer) ratio" for ionic polymeric additives in preclinical tests rather than an "optimal (polymer) concentration" used previously for nonionic polymers.
Overall, at the very low concentrations tested here, chitosan significantly improves the surface activity of a dilute BLES preparation and reverses the inhibitory effects of albumin. The present in vitro study hence suggests that chitosan is a promising additive to lipid extract surfactants. It will be of interest to investigate the effectiveness of chitosan with other therapeutic surfactants, as well as its efficacy in animal models.

Acknowledgments. The authors thank Dr. David Bjarneson of BLES Biochemicals, Inc., for his generous donation of the BLES samples.

\section{REFERENCES}

1. Taeusch HW, Lu KW, Goerke J, Clements JA 1999 Nonionic polymers reverse inactivation of surfactant by meconium and other substances. Am J Respir Crit Care Med 159:1391-1395

2. Kobayashi T, Ohta K, Tashiro K, Nishizuka K, Chen WM, Ohmura S, Yamamoto K 1999 Dextran restores albumin-inhibited surface activity of pulmonary surfactant extract. J Appl Physiol 86:1778-1784

3. Tashiro K, Kobayashi T, Robertson B 2000 Dextran reduces surfactant inhibition by meconium. Acta Paediatr 89:1439-1445

4. Lu JJ, Cheung WW, Yu LM, Policova Z, Li D, Hair ML, Neumann AW 2002 The effect of dextran to restore the activity of pulmonary surfactant inhibited by albumin. Respir Physiol Neurobiol 130:169-179

5. Yu LM, Lu JJ, Chiu IW, Leung KS, Chan YW, Zhang L, Policova Z, Hair ML, Neumann AW 2004 Poly(ethylene glycol) enhances the surface activity of a pulmonary surfactant. Colloids Surf B Biointerfaces 36:167-176

6. Taeusch HW, de la Serna JB, Perez-Gil J, Alonso C, Zasadzinski JA 2005 Inactivation of pulmonary surfactant by serum: mechanisms of reduced adsorption and its reversal by hydrophilic polymers: experimental. Biophys J 89:1769-1779

7. Lu KW, Taeusch HW, Robertson B, Goerke J, Clements JA 2000 Polymersurfactant treatment of meconium-induced acute lung injury. Am J Respir Crit Care Med 162:623-628

8. Lu KW, Taeusch HW, Robertson B, Goerke J, Clements JA 2001 Polyethylene glycol/surfactant mixtures improve lung function after $\mathrm{HCl}$ and endotoxin lung injuries. Am J Respir Crit Care Med 164:1531-1536

9. Lu KW, Robertson B, Taeusch HW 2005 Dextran or polyethylene glycol added to curosurf for treatment of meconium lung injury in rats. Biol Neonate 88:46-53

10. Lu KW, Goerke J, Clements JA, Taeusch HW 2005 Hyaluronan decreases surfactant inactivation in vitro. Pediatr Res 57:237-241

11. Lu KW, Goerke J, Clements JA, Taeusch HW 2005 Hyaluronan reduces surfactant inhibition and improves rat lung function after meconium injury. Pediatr Res 58:206-210

12. Kumar MN, Muzzarelli RA, Muzzarelli C, Sashiwa H, Domb AJ 2004 Chitosan chemistry and pharmaceutical perspectives. Chem Rev 104:6017-6084

13. Aspden TJ, Mason JD, Jones NS, Lowe J, Skaugrud O, Illum L 1997 Chitosan as a nasal delivery system: the effect of chitosan solutions on in vitro and in vivo mucociliary transport rates in human turbinates and volunteers. J Pharm Sci 86:509513

14. Chan V, Mao HQ, Leong KW 2001 Chitosan-induced perturbation of dipalmitoylsn-glycero-3-phosphocholine membrane bilayer. Langmuir 17:3749-3756

15. Fang N, Chan V, Mao HQ, Leong KW 2001 Interactions of phospholipid bilayer with chitosan: effect of molecular weight and $\mathrm{pH}$. Biomacromolecules 2:1161-1168

16. Fang N, Chan V 2003 Interaction of liposome with immobilized chitosan during main phase transition. Biomacromolecules 4:581-588

17. Fang N, Chan V 2003 Chitosan-induced restructuration of a mica-supported phospholipid bilayer: an atomic force microscopy study. Biomacromolecules 4:15961604

18. Yu LM, Lu JJ, Chan YW, Ng A, Zhang L, Hoorfar M, Policova Z, Grundke K, Neumann AW 2004 The constrained sessile drop as a new configuration to measure low surface tension in lung surfactant systems. J Appl Physiol 97:704-715

19. Wang T, Turhan M, Gunasekaran S 2004 Selected properties of pH-sensitive, biodegradable chitosan-poly(vinyl alcohol) hydrogel. Polym Int 53:911-918

20. Ishizaka A, Matsuda T, Albertine K, Koh H, Tasaka S, Hasegawa N, Kohno N, Kotani T, Morisaki H, Takeda J, Nakamura M, Fang X, Martin T, Matthay M, Hashimoto S 2004 Elevation of kl-6, a lung epithelial cell marker, in plasma and epithelial lining fluid in ARDS. Am J Physiol Lung Cell Mol Physiol 286:L1088L1094

21. Zuo YY, Gitiafroz R, Acosta E, Policova Z, Cox PN, Hair ML, Neumann AW 2005 The effect of humidity on the adsorption kinetics of lung surfactant at air-water interfaces. Langmuir 21:10593-10601

22. Possmayer F 1997 Physicochemical aspects of pulmonary surfactant. In: Polin RA, Fox WW (eds) Fetal and Neonatal Physiology, 3rd Ed. WB Saunders, Philadelphia, pp 1259-1275

23. Bachofen H, Schürch S, Urbinelli M, Weibel ER 1987 Relations among alveolar surface tension, surface area, volume, and recoil pressure. J Appl Physiol 62:18781887

24. Rio OI, Neumann AW 1997 Axisymmetric drop shape analysis: computational methods for the measurement of interfacial properties from the shape and dimensions of pendant and sessile drops. J Colloid Interface Sci 196:136-147 
25. Agu RU, Valiveti S, Earles DC, Klausner M, Hayden PJ, Wermeling DP, Stinchcomb AL 2004 Intranasal delivery of recombinant human parathyroid hormone [hPTH (1-34)], teriparatide in rats. Endocr Res 30:455-467

26. Warriner HE, Ding J, Waring AJ, Zasadzinski JA 2002 A concentration-dependent mechanism by which serum albumin inactivates replacement lung surfactants. Biophys J 82:835-842

27. Holm BA, Wang ZD, Notter RH 1999 Multiple mechanisms of lung surfactant inhibition. Pediatr Res 46:85-93

28. Zasadzinski JA, Alig TF, Alonso C, de la Serna JB, Perez-Gil J, Taeusch HW 2005 Inactivation of pulmonary surfactant by serum: mechanisms of reduced adsorption and its reversal by hydrophilic polymers: theory. Biophys J 89:1621-1629

29. Dehority W, Lu KW, Clements J, Goerke J, Pittet JF, Allen L, Taeusch HW 2005 Polyethylene glycol-surfactant for lavage lung injury in rats. Pediatr Res 58:913-918

30. Meyuhas D, Nir S, Lichtenberg D 1996 Aggregation of phospholipid vesicles by water-soluble polymers. Biophys J 71:2602-2612

31. Putz G, Goerke J, Clements JA 1994 Surface activity of rabbit pulmonary surfactant subfractions at different concentrations in a captive bubble. J Appl Physiol 77:597-605

32. Brackenbury AM, Malloy JL, McCaig LA, Yao LJ, Veldhuizen RA, Lewis JF 2002 Evaluation of alveolar surfactant aggregates in vitro and in vivo. Eur Respir $\mathrm{J}$ $19: 41-46$
33. Sorlier P, Denuziere A, Viton C, Domard A, 2001 Relation between the degree of acetylation and the electrostatic properties of chitin and chitosan. Biomacromolecules 2:765-772

34. Nielson DW, Goerke J, Clements JA 1981 Alveolar subphase pH in the lungs of anesthetized rabbits. Proc Natl Acad Sci U S A 78:7119-7112

35. Thongngam M, McClements DJ 2005 Influence of $\mathrm{pH}$, ionic strength, and temperature on self-association and interactions of sodium dodecyl sulfate in the absence and presence of chitosan. Langmuir 21:79-86

36. Rodriguez-Capote K, Nag K, Schurch S, Possmayer F 2001 Surfactant protein interactions with neutral and acidic phospholipid films. Am J Physiol Lung Cell Mol Physiol 281:231-242

37. Alig TF, Warriner HE, Lee L, Zasadzinski JA 2004 Electrostatic barrier to recovery of dipalmitoylphosphatidylglycerol monolayers after collapse. Biophys J 86:897904

38. Boncuk P, Kaser M, Yu Y, Taeusch HW 1997 Effects of cationic liposome-DNA complexes on pulmonary surfactant function in vitro and in vivo. Lipids 32:247253

39. Bummer PM, Aziz S, Gillespie MN 1995 Inhibition of pulmonary surfactant biophysical activity by cationic polyamino acids. Pharm Res 12:1658-1663 